\title{
Reflections on the Heuristic Experiences of a Multidisciplinary Team Trying to Bring the PCA to Participatory Design (with emphasis on the IPR method)
}

\author{
Sarah Kettley \\ Nottingham Trent University \\ Burton Street \\ Nottingham, NG1 4BU, UK \\ sarah.kettley@ntu.ac.uk \\ Matthew Bates \\ Nottingham Trent University \\ Burton Street \\ Nottingham, NG1 4BU, UK \\ matthew.bates@ntu.ac.uk \\ Permission to make digital or hard copies of all or part of this work for \\ personal or classroom use is granted without fee provided that copies \\ are not made or distributed for profit or commercial advantage and \\ that copies bear this notice and the full citation on the first page \\ Copyrights for components of this work owned by others than ACM \\ must be honored. Abstracting with credit is permitted. To copy \\ otherwise, or republish, to post on servers or to redistribute to lists, \\ requires pro lists, \\ requires prior specific permission and/or a fee. Request permissions
from Permissions@acm.org. \\ Ubicomp/ISWC'15 Adjunct, September 07-11, 2015, Osaka, Japan \\ (C) 2015 ACM. ISBN 978-1-4503-3575-1/15/09...\$15.00 \\ DOI: http://dx.doi.org/10.1145/2800835.2807946
}

\begin{abstract}
This paper introduces a heuristic case study, reflecting on the use of the Interpersonal Process Recall (IPR) method as part of An Internet of Soft Things, a multidisciplinary design research project working with the UK mental health charity, Mind. The three authors represent three different disciplines within the project Psychotherapy, e-Textiles, and Human-Computer Interaction - and naturally bring their own experiences and expectations to the multidisciplinary team process. The aim of the project is to develop, through practice, a methodology for a Person-Centred Approach to design, informed by the theories and practice of Carl Rogers, and thereby to address the increasing need for researcher reflection in Participatory Design. The paper outlines the project and describes our experiences of IPR within it; it discusses how we are taking this work forward and closes with some guidelines based on our personal observations in working with this method.
\end{abstract}




\section{Author Keywords}

Reflection; Participatory Design; team working; wellbeing; phenomenological methods; ethics.

\section{ACM Classification Keywords}

].4 [Social And Behavioral Sciences]: Psychology; K.4.1 [Public Policy Issues]: Ethics.

\section{Introduction}

Recent calls for reflexivity in HCI [28] have pointed out the need for design researchers to be explicitly reflexive in their practice when working with participants; others point out that this need is intensified when members of design research teams come from different disciplinary backgrounds, and have different mindsets and expectations [21]. Reflection is needed not only to enable a healthy researcherparticipant relationship, but to support individual researchers as they are challenged by the process [8], [16]; we need to reflect both on the user experience of participatory design, and on the design team experience. This paper accompanies two others also presented at UbiComp2015 on our use of Carl Rogers' Person-Centred Approach as a guiding framework for the research [10], [20] and an outline of the IPR method [9]. This paper presents two personal accounts of what it was like to experience being a 'Recaller' for the first time in an IPR process, and reflects on the method as a way of supporting researchers in fields that may cause 'vicarious trauma' [10], and of creating a culture of continuing profesisonal developemnt through self-reflection.

\section{Context}

An Internet of Soft Things is a multidisciplinary project involving computer science, textile design, interaction design, and psychotherapy practice led by Nottingham Trent University in collaboration with Nottinghamshire Mind Network. This network comprises five individual charities affiliated with the UK national Mind organisation, working together to optimise research and service delivery in the field of mental health and wellbeing [17]. Mind is the UK's largest mental health charity; they take an inclusive non-diagnostic approach and provide a range of services to the public, as well as working to de-stigmatize mental illness and raise awareness of the nature of mental health issues. The project recognises that public imaginaries of future technologies, such as the Internet of Things (IOT) and 'smart' textiles tend to be written by those with significant social and cultural capital, such as technology labs, design studios and associated media, science fiction novelists, and film-makers, although as Michael points out, they are not monolithic and increaseingly invite the layperson to "contribute to the process of technoscientific decision or policy making"

[15:63]. The experience of people accessing services at Mind tend to include a loss of such capital; they often report feeling unheard by mainstream health services more aligned to treating physical problems and pathologies, and frequently feel 'done to' by systems (even those designed to help) [18], [30]. The potential for a future enabled by over 26 billion wirelessly networked things [25] to reproduce such

disempowering systems is considerable, and we believe a critically reflective approach is needed to IoT

development in order to support positive mental health in the future. As a special interest group in the UK put it, " the scale of the IoT could dwarf that of the Internet of today. The potential scale of its societal implications is equally enormous." [26:1]. 
The project seeks to contribute to participatory design methodologies through an analysis of Rogers' PersonCentred Approach, in which the voice of the individual is prized [20]. It is comprised of four phases: 1 ) etextile workshops at the handheld scale; 2 ) e-textile workshops with networking at the domestic interior scale; 3) excursions into 'the wild' with networked etextile objects; and 4) a Future Workshop to devise and implement a new venue and innovative services for Mind in central Nottingham.

\section{Pilot Study}

The first phase was piloted between October and December 2014. Participants were recruited from the project team and through talks at the University. Our original intention was that the participants would be Mind service users, but recruitment in mental health is a separate issue for participatory design research that needs to be reflected on. Aspects such as confidence in the content of workshops, the unknown new relationships, feelings of safety in large groups, and anxiety over travel, all play a part; the first phase of workshops held in early 2015 did comprise an existing group of service users, once these issues had been addressed. In the meantime, we ran a series of six weekly e-textile workshops, each three hours long. The final group of participants included The PI, both CoIs, one of the RFs in computer science, the business manager from the Mind network (also on the project advisory board), the Mind development manager, two current final year product design students, and one recent product design graduate.

Two members of the research team - the RF in Textiles, and a PhD student, maintained facilitator roles throughout. The two counselors from the team also facilitated but occasionally segued into participant roles. We were also joined by the researcher in patterncutting for the last three sessions, and she played a facilitator role.

\section{Questions on Configuring Mental Health Participants in Design}

We were initially disappointed and concerned for the validity of the pilot study as a result of apparently having no service users on board. However, this gave rise to interesting methodological reflections on how design research thinks about and configures mental health participants. As stated, Mind takes a nondiagnostic view of mental health: that is, Mind does not diagnose and prescribe medicine, but can refer individuals to other agencies where necessary, while offering a point of contact and support for those in crisis. Individuals can become members of Mind, which gives them access to supportive activity groups and a range of talking therapies. The pilot workshops we ran differed from the Mind process in that we treated the sessions as open access; participants were not assessed before taking part. Therapists and agencies like Mind need to have awareness of personal and medical history, and conduct an assessment to allow the individual to access services. Open access groups, on the other hand, are not assessed, and are understood to be therapeutic, while not being therapy.

One of the reasons for this difference is the project's enquiry into the Person-Centred Approach (PCA) as a framework for participatory design [10], [11]. While an individual accessing Person-Centred therapy would have been through an assessment, the therapeutic process is organised around a diagnosis. For example, in contrast with Psychodynamic and Gestalt therapies, 
the client is not directed to dwell on their condition or specific traumatic episodes; rather, it is the attitude of unconditional positive regard in listening that is understood to be therapeutic, and it is up to the client what they bring to the discussion, and when [11]. In Denis Roche's words, it seeks to put in place the conditions for new processes to take root, rather than doing something to the individual [19]. Therefore, our approach differs also from many design-for-health research projects, which start with a demographic or common condition, and does not take a standard problem-solving approach to design or to mental health (and this is what we would mean by 'inclusive'). Such an inclusive, person-centred approach can make it hard to answer funding and innovation calls, which are also often written from a problem-solving perspective [5], despite being pertinent to all of these issues. Perhaps this approach is suitable as a response to the UK Foresight report on mental capital and wellbeing, in which the authors emphasise that:

"Whilst it is important for Government to address problems that affect the mental development of specific groups, such as learning difficulties and mental disorders, policies and choices also need to nurture the mental capital and wellbeing in the wider population, so that everyone can flourish throughout their lives" $[7: 10]$.

Thus, the pilot study not only informed the design and delivery of the phase one workshops [6], but also helped us to articulate that while 'we all have mental health', the nature of groups can be diverse, and include: mental health in the general population; mental health in organisations such as Mind; and (as we continue our work at Oakfield School, Nottingham), mental health alongside learning and physical disabilities. Finally, for designers working for the first time in these areas, it is important to note that training helps to alleviate personal concerns, provide support to researchers, and prepare the ground for ethical

treatment of participants [4]. In the course of our six weeks working together, it transpired that several of our pilot study participants had in fact accessed counselling services, or described themselves as having lived experience of mental health issues. Arguably, the convivial nature of making together creates the very context for sharing such personal information [3] [13].

In the course of the mental health awareness training delivered to the team by Mind [4], it was also clear that most of us could identify moments or periods in our lives when in fact we could have been diagnosed with anxiety or depression had we presented at our local GP surgery (the medical definition of depression is if an individual experiences feelings of being low for as little as two weeks); frightening and severe physical symptoms some of us had experienced, such as chest pain and difficulty breathing, are recognised to be common outcomes of sustained stress. A combination of the inclusive statistics for mental health (one in four of us will experience mental health issues at some point in our lives) [14], in addition to the self-selecting nature of participants in response to recruitment, appears to have been effective in bringing together a relevant participant group for this stage in the project. The Person-Centred Approach would support this attitude to inclusivity and non-directiveness, although it challenges the more normal scientific approaches to selecting research respondents. The process has also highlighted implications for supporting research teams, suggesting we need to recognise them as individuals as 
much as our research participants, who are likely to be impacted emotionally by their work [8], [16], [27].

We used IPR as a method in the pilot phase, with the aim of understanding how we were trying to enact the Person-Centred attitude, but also as a way of bringing to the fore the personal experience of the researcher in the process.

\section{What is IPR?}

Interpersonal Process Recall (IPR) is a method in which an interaction is audio-video captured, with the intention of at least one participant using it to later reflect on the experience of the interaction (the 'Recaller'). This process is supported by a second individual acting in the role of 'Inquirer'. The Recaller controls the AV playback, and is guided in their verbalised reflections on what they were feeling, thinking and experiencing at any given moment in the original interaction. IPR has been used in social work [12], education [22] and therapeutic practices [1], [2] as a way of supporting continous professional development. We give a fuller account of how to set up and run an IPR session in [9]. This paper presents the experiences of two of our research team as they engaged with IPR for the first time as part of the pilot study described above. These are heuristic, first person accounts in response to re-reading the transcripts of the recall sessions (in IPR, the AV recording is destroyed after the recall session for ethical reasons). The first Recaller was filmed while engaged in a design process as part of the convivial e-textile workshop; she could be said to have been in conversation with the materials at hand rather than with other people [23]. The second Recaller took part in a Mutual Recall session, in which two or more people are recorded together, and both engage in the recall session (either separately or together). In this case, both participated in the recall session, although only one reports here.

\section{Reflections on IPR Experience}

Individual Recall (Sarah, first author)

I agreed to be video-ed by Richard (third author) in the fourth week of the pilot workshops. I remember feeling quite self-aware with the camera on its little gorilla tripod pointing at me - I felt like I was performing the design process somewhat, and that was a bit nervewracking, as I haven't had a chance to do design as such for a long time (I've been too busy teaching and being an academic). Especially, the team had put together carboard folders with notebooks, pencils, postits etc in them for each participant, and I felt like I was supposed to use the A5 sketchbook. In this workshop I was starting to explore interaction ideas with magnetic switches - I wanted to create two textile parts that would come together as a switch, and was trying to apply this to an earlier form that I'd wanted to develop for a number of years (the HUG ball, originally made in 2007 ) - so that added to the pressure I was putting on myself to perform design. That moment of anxiety obviously didn't last long though - in the transcript I notice that the video is more than ten minutes long, but say "it felt like two minutes to me - it just went really fast". Whether I was self-aware or not, it seems I found the design process satisfying and immersive; there is a lot of decription of the materiality of working, including of the pencil I was using to write with, which was "grainy and harsh"; my immersion in the material can be seen in the phrase "and then I'm back in the masking tape and the fabric again". I can obviously see in my process the relationship between concept and 
material being played out; the experience of watching this back and describing it is illuminating and exciting as a research this is one of my areas of interest - so the IPR method reveals itself to me as extremely exciting on another, meta level, as a researcher looking for interesting methods for craft and cognition research. Experiencing it myself suggests how it might feel for other makers to do it too. As a heuristic process, the reflection also helped me to recognise and work through the multiply-faceted role I was playing in the project: I was the Principal Investigator who had initiated the project and was responsible for its delivering against UKRC funding; I was responsible for the management and leadership of individuals in a large and diverse team; I was at the same time dissertation tutor to one of the final year students, and had taught both other students at different times on UG Product Design courses; was director of studies for the PhD student who was acting as one of the facilitators; I was aware that both of the CoIs had far more academic experience than myself, including in running projects; and I was married to Richard, the RF leading the IPR session. And yet in this e-textile workshop I was primarily a participant with some lived experience of mental health issues, making soft switches and embedding sensors into textile objects. In that role, I was aware of my own past as a jeweller, and the new spaces I was exploring in textiles and inetraction design. I carried with me some self-perception as being creative and "good at" making, if not the kind of design my students are used to. Being shown all of this in action in the video playback was illuminating - it seemed on reflection OK for this project to feel complex, intense and layered, and perhaps not like other projects might be experienced. It highlighted a need for self-care if we are to bring a lot of ourselves to participatory processes as researchers. At the same time, the session recorded shows that at this point at least, there was a kind of hiatus, and that I was very happy with how things were going ("I feel comfortable in letting everything else carry on"), confident in my research team ("it felt very supportive and supported"), and validated in our approach to the project ("it kind of validates all the work that we've put in...and the way we've configured the methodology"). The IPR process itself surprised me - it had sounded complicated when described (who sees the playback, who does what etc), but I experienced it as enagaging and straightfoward. It felt safe bvecause I was in control of stopping the video - and I found I stopped it far more than I had expected to. We ended up reviewing only three minutes of footage, but this took about forty-five minutes to work through. I was also intrigued that this interaction - with design materials rather than with another person seemed to expand the moment; after those three minutes, I suggest that "I could be saying exactly the same things [about how I'm feeling and what I'm doing] for the next five or ten minutes". It would be interesting now to experience IPR in reflecting on a person-person interaction.

\section{Mutual Recall (Matthew, second author)}

Initially, the concept of IPR was unfamiliar to me as a research technique. Video-capture has been used in my previous work as a method of recording and transcribing presentations of project results from the perspective of the participant. These presentations have involved several participants (target learners, teachers, stakeholders) and so the use of video capture was beneficial here as the visual cues could be used to identify and discern between different speakers and 
contributors during these activities. When approached by the workshop facilitators to engage with a process of IPR, I was enthusiastic to participate with the activity in order to revisit the interactions which took place as part of the design workshop (the event) and the IPR process in general (the objective). As the IPR activity took place the morning after the event, I was able to recollect some information relating to my aims and objectives for participation. I decided however not to use or refer to researcher notes either before or during the activity in order to be open-minded about the approach and my recollection of events. The IPR activity was also attended by my co-designer from the workshop event and two therapists from the project acting as 'Inquirers'. At the start of the activity, I immediately attempted to make sense of the images by trying to recall what I was doing (action) and my thought process at the time (motivation). The audio recording was unfortunately distorted and so the audible discussion topics were not immediately obvious. This initial lack of stimulus encouraged me to describe the visible interactions and attempt to explain and rationalise them in the presence of my co-designer. This dynamic of reviewing the recording as a pair made the process of discussing the activities with investigators much easier as each observable interaction could be discussed from multiple perspectives.

The process also allowed us (as participants with IPR) to continue to share our thoughts about the creation of the wearable article beyond the shared space of the design workshop. This created opportunities for me in particular (as participant to the workshop activities) to acknowledge the support and assistance I had received during the workshop and to share my appreciation for the ease with which the garment was assembled, something which I was originally surprised had occurred. Comments expressed at the time such as "it felt like the idea had been validated and that really gave me the push to go forward and complete it with your assistance" support this view. The IPR activity also presented me with an opportunity to review the wider process of working in a person-centric environment (an activity new to me at the time) by comparing the tangible outputs of the workshop process to my initial expectations going into the pilot study. Upon reflection, I found the IPR activity useful as it served to both improve my understanding of IPR as a tool and to strengthen my relationship with my co-researchers as part of a multi-disciplinary approach to designing and working. Comments expressed at the time such as "I felt so comfortable with the working environment and with the working relationship that once we had actually tackled those initial problems, how to attach the circuit to the garment, the rest of it seemed to fall into place quite naturally" support this view.

\section{Closing Comments and Further Work}

We found this to be a very powerful reflective tool for the researchers that took part. Both were participants in the workshop, and so reflections tended to be on learning and dual roles rather than on our growing confidence with the Person-Centred attitude, which would be helpful to the project; this is something we are working to correct in the second phase of An Internet of Soft Things, as we work with participants to co-design product-service systems for mental health. Using IPR with mental health service users at Mind is not an option - their involvement in the participatory design workshops is already a significant achievement for most of them, and our informed consent allows still 
images, with no faces. We have, however, since invited participants to reminisce about their experiences with us, and have made three short films of three individuals, with whom we co-developed personalised informed consent forms. This is an interesting direction which we also intend to develop further, informed by the recent interest in 'embodied interaction research techniques' [29]. Further, we understand that the history of IPR itself has an impact on how it is being used and developed by researchers in different disciplines; articulating this would foreground how the technique may be more or less in line with PersonCentred values for example [24:98-99], and let design researchers make informed decisions about their own use of the method.

Our final recommendation is quite broad: reflection like this can be personally challenging for individuals, and may not be what members of a research team feel they have signed up for [10]. Asking people to reflect means we have a responsibility to provide a safe and supportive environment, particularly in the context of design research with mental health. In the counseling profession, it is standard practice for practitioners to attend supervision sessions with an experienced practising counsellor to discuss experiences and issues arising with clients (at a ratio of one hour to every four hours for trainees, and every one in eight for early career UKCP registered professionals). This helps to create professional consensus on practice and a supportive professional network, essential for the wellbeing and continuing professional development of the individual practitioner. We believe that as design research becomes more involved in domains that have the potential to impact on our wellbeing, it would also benefit from such a structured approach to support for researchers.

\section{Acknowledgements}

We thank all the participants who took part in our pilot study in Nottingham in 2014, and the Bassetlaw Mind service users, staff and volunteers who contributed to the participatory design workshops in 2015. This work has been made possible through an EPSRC Researchin-the-Wild grant EP/L023601/1.

\section{References}

[1] Allen, P. The Use of Interpersonal Process Recall (IPR) in Person-Centred Supervision (2004). In K. Tudor and M. Worrall (Eds.). Freedom To Practice: Person-Centred Approaches to Supervision, PCCS Books, Ross-on-Wye, 2004, 153-170.

[2] Angus, L., Watson, J. C., Elliott, R., Schneider, K. and Timulak, L. Humanistic psychotherapy research 1990-2015: From methodological innovation to evidence-supported treatment outcomes and beyond. Psychotherapy Research 25, 3 (2014), 1-18.

[3] Baggerman, M. (Ed.). Social Fabric. Design Academy Eindhoven, Eindhoven, 2013.

[4] Berry, H. and Roberts, N. Mental Health Awareness, 2015.

http://aninternetofsoftthings.com/mental-healthawareness-training/

[5] Design Council. Living Well with Dementia Design Challenge Report. Design Council, London, 2012.

[6] Glazzard, M., Kettley, R., Kettley, S., Walker, S., Lucas, R. and Bates, M. Facilitating a 'non-judgmental' skills-based co-design environment. Proc. $3^{\text {rd }}$ European Design4Health Conference, 2015.

[7] The Government Office for Science. Foresight Mental Capital and Wellbeing Project. Final Project report. London, 2008.

https://www.gov.uk/government/publications/mentalcapital-and-wellbeing-making-the-most-of-ourselvesin-the-21st-century. 
[8] Jurmu, M., Ylipulli, J. and Luusua, A. I've Had It! Group therapy for interdisciplinary researchers. Ext. Abstracts Critical Alternatives, (2015).

[9] Kettley, S., Kettley, R. and Bates, M. An Introduction to the Person-Centred Approach as an Attitude for Participatory Design. Adjunct Proc.

Ubicomp/ISWC'15, ACM Press (2015).

[10] Kettley, S., Kettley, R. and Lucas, R. Personalized or Person-Centred Design? In T. Fisher \& I. Kuksa

(Eds.). Design for Personalisation. Gower, Farnham, forthcoming.

[11] Larsen, D., Flesaker, K. and Stege, R. Qualitative Interviewing Using Interpersonal Process Recall:

Investigating Internal Experiences during ProfessionalClient Conversations. International Journal of Qualitative Methods 7, 1 (2008), 18-37.

[12] Mayne, A. Woolly Wellbeing. Adjunct Proc. $3^{\text {rd }}$ European Design4Health Conference, 2015.

[13] Mental Health Foundation. Mental Health Statistics. http://www.mentalhealth.org.uk/helpinformation/mental-health-statistics/.

[14] Michael, M. Technoscience and Everyday Life. Open University Press, Maidenhead, 2006.

[15] Moncur, M. The emotional wellbeing of researchers: considerations for practice. Proc. CHI (2013), 18831890.

[16] Notts Mind Network.

http://nottsmindnetwork.co.uk/

[17] Proctor, G., Cooper, M., Sanders, P. and Malcolm, B. Politicising the Person-Centred Approach: An Agenda for Social Change. PCCS Books, Ross-on-Wye, 2006.

[18] Roche, D. Open Window Project. The Sackler Conference, V\&A Museum, London, 2015.

[19] Rogers, C. R. A Theory of Therapy, Personality and Interpersonal Relationships, as Developed in the ClientCentred Framework (1957). In H. Kirschenbaum and V. L. Henderson (Eds.). The Carl Rogers Reader.

Constable, London, 1990, 219-235.
[20] Sanders, E. On Modeling: An Evolving Map of Design Practice and Design Research. ACM Interactions, $X V, 6$ (2008), 13-17.

[21] Scaife, ] The development of under-standing in pastoral care: an innovative approach using Interpersonal Process Recall (1998). In M. Calvert and J. Henderson (Eds.). Managing Pastoral Care London: Cassell, 1998, 127-140.

[22] Schön, D. The Reflective Practitioner: How professionals think in action. Basic Books, New York, 1983.

[23] Shipton, G. (Ed.). Supervision of Psychotherapy and Counselling. Open University Press, Buckingham, 1997.

[24] Siemens 2014. Internet of Things.

http://www.siemens.com/innovation/en/home/pictures

-of-the-future/digitalization-and-software/internet-ofthings-facts-and-forecasts.html

[25] Technology Strategy Board. A Roadmap for Interdisciplinary Research on the Internet of Things. 2012.

https://connect.innovateuk.org/documents/3077922/3 726361/IoT\%20Research\%20Roadmapping\%20\%20Final\%20Report.pdf.

[26] Treadaway, C., Kenning, G. and Coleman, S. Sensor e-Textiles: Designing for persons with late stage dementia. Proc. $3^{\text {rd }}$ European Design4Health Conference, 2015.

[27] Vines, J., Clarke, R., Wright, P, McCarthy, J. and Olivier, P. Configuring Participation: On How We Involve People In Design. Proc. CHI (2013), 429-438.

[28] Wilde, D. and Tomico, O. Track 2: Design Films. Shaping (un)common Grounds. Arcintex Network Conference, 2014. http://arcintex.hb.se/conferencesworkshops/

[29] Wilkins, P. Person-Centred Therapy: 100 Key Points. Routledge, Hove, 2010, 13-16. 